\title{
Parintins: palco de guerras tribais
}

\author{
Max Deulen Baraúna Nogueira \\ Instituto Federal do Amazonas (IFAM) \\ (maxdeulen@hotmail.com)
}

Resumo: A ilha de Parintins foi palco de guerras inter-étnicas, entre os séculos XVII e VXIII na Amazônia colonial, onde vários grupos étnicos habitavam e viviam. A problemática desse trabalho é procurar nas fontes o porquê que faziam guerra contra a etnia Mura. O objetivo geral desse trabalho é fazer uma pesquisa historiográfica sobre as guerras inter-étnicas (guerra intertribal) entre os povos indígenas que habitavam o período da Amazônia Colonial e o objetivo específico é analisar a guerra contra o grupo étnico Mura pelo grupo étnico Mundurucu. A metodologia empregada é a pesquisa historiográfica nas fontes primárias, que se encontram em arquivos, museus e bibliotecas públicas do Amazonas. O resultado dessa pesquisa é que, pela ferocidade e belicosidade dessas tribos, eles conseguiram sobreviver no tempo, não foram exterminadas como tantas dezenas de outros grupos étnicos que foram exterminados em contato com os europeus. Concluímos que é necessário fazer um resgate desses personagens, outorgar-lhes um protagonismo esquecido que eles merecem, resgatar suas lutas e suas glórias por esses brasileiros que não aceitaram a conquista da Amazônia.

Palavras-Chaves: Parintins; Guerras; Tribos Indígenas.

\section{Parintins: tribal war scene}

\begin{abstract}
The island of Parintins was the scene of inter-ethnic wars between the seventeenth and eighteenth centuries in the colonial Amazon where several ethnic groups inhabited and lived in it. The problem of this work is to look for the sources why they made war against the Mura ethnic group? The general objective of this work is to make a historiographic research on the inter-tribal wars between the indigenous peoples who inhabited the period of Colonial Amazonia and the specific objectives is to analyze the war against the Mura ethnic group by the Mundurucu ethnic group. The methodology used is the historiographic research in the primary sources found in archives, museums and public libraries of Amazonas. The result of this research is that because of the ferocity and bellicosity of these tribes they managed to survive in time, they were not exterminated like so many dozens of other ethnic groups that were exterminated in contact with the Europeans. We conclude that it is necessary to rescue these characters, to grant them a forgotten protagonism that they deserve, to rescue their struggles and their glories for those Brazilians who did not accept the conquest of the Amazon.
\end{abstract}

Keywords: Parintins; Wars; Indian tribes.

\section{INTRODUÇÃO}

Na Amazônia colonial, dos séculos XVII e XVII, a ilha de Parintins foi palco de várias guerras intertribais e vários grupos étnicos habitaram essa ilha e nela viveram, como nos conta o diário de Carvajal (1986), frade dominicano que acompanhava a viagem do capitão espanhol Francisco Orellana, hoje exposto no 
museu de Madri, que relata a passagem por um povoado, e que viram às margens do mesmo rio estacas com cabeças de índios secas e espetadas. Deram ao povoado o nome de Las Picotas, e, logo depois, passavam pela serra de Parintins, que denominaram de Sierra Grand (Serra Grande), em 23 de junho de 1542, véspera de São João.

Essa é a primeira vez que se fala na ilha, outros padres, só que da Companhia de Jesus, chamados Cristóbal de Acunã e Andrés de Artieda, que tinham a qualidade e a devida autoridade em nome do Rei Filipe IV da Espanha de serem as testemunhas oculares das informações coletadas do longo trajeto acerca da região percorrida, seus habitantes e suas riquezas, na companhia do CapitãoMor Pedro Teixeira, nos contam que:

As vinte e oito léguas da boca deste rio, seguindo-se sempre pela mesma banda sul, há uma formosa ilha que tem sessenta léguas de comprimento e, consequentemente, mais de cem de circunferência, toda povoada pelos valentes Tupinambás, gentio que, após a conquista do Brasil, em terras de Pernambuco, há muitos anos, saiu derrotada, fugindo do rigor com que os portugueses o sujeitavam. Saíram em tão grande número, que, despovoando ao mesmo tempo oitenta e quatro aldeias onde viviam, não restou sequer que não trouxessem consigo. (ACUNÃ, 1641, p.148)

A ilha já era conhecida no mundo, quase 100 anos depois do primeiro relato, ora por suas paragens e belezas naturais, ora por suas tribos, muitos desses que por sinal sucumbiram, desapareceram, ou foram exterminados sem dúvida, a história nos mostra que os índios têm sido os conquistados, e os brancos, os conquistadores. Esta mesma história é que é sempre contada pelos vencedores. A verdade do derrotado não é ouvida, muito menos lida, já que, via de regra, não existia a escrita entre os nativos.

O que nos deixa abismados é por qual motivo tanta tribo inimiga convivia num mesmo local? Uma explicação vem do que escreveu Baena (apud Bernadino de Souza, 1873) sobre as tribos mencionadas na llha de Parintins.

É muito rica em madeiras da melhor qualidade, sobressaindo entre todas a bella Muirapinima. Dizem que há também ali Páo-Brasil; entretanto nenhum dado seguro há para poder asseverar a sua existência. (BAENA, 1893, p. 36)

Outra crença que une as tribos no mesmo local são seus ritos, suas crenças e suas religiões serem quase iguais, principalmente os ritos de iniciação dos meninos 
onde alcançam a fase adulta, onde possam a ser chamados de guerreiros. Nesse sentido, surge a problemática, que é descobrir o significado da Guerra contra a etnia mura.

O objetivo geral desse trabalho é fazer uma pesquisa historiográfica sobre as guerras inter-étnicas (guerra intertribal) entre os povos indígenas que habitavam o período da Amazônia Colonial. E o objetivo específico é analisar a guerra contra o grupo étnico Mura pelo grupo étnico Mundurucu.

\section{MATERIAL E MÉTODO}

Faz-se necessária uma análise sobre os documentos históricos de textos escritos sobre as tribos que habitavam a ilha de Parintins e adjacências e o que motivavam a guerra entre si, principalmente entre o ódio mortal entre os Muras e os Mundurucus.

O trabalho foi desenvolvido por uma pesquisa bibliográfica em fontes documentais que estão nos arquivos do Museu Amazônico, arquivos do Instituto Geográfico e histórico do Amazonas, arquivo digital do Museu Ultramarino de Portugal, base de dados da Scielo e outras bases de teses e dissertações acerca dos documentos e registros históricos desses acontecimentos sobre as guerras tribais na ilha de Parintins e das tribos envolvidas.

Levantamento de material bibliográfico para um estudo do tipo descritivo, realizado através de livros, que, segundo Lakatos (2006), é caracterizado por abranger toda bibliografia publicada em relação ao tema de estudo, desde publicações avulsas, boletins, jornais, revistas, pesquisas, monografias, teses e meios de comunicações visuais e auditivas. A finalidade é proporcionar ao pesquisador o contato direto com todos os métodos de divulgação sobre 0 determinado assunto.

Como concorda Gil (2002), uma pesquisa bibliográfica é definida como um estudo que toma partida de material já elaborado, constituído por vários livros de literatura corrente, livros de referência informativa e remissiva, como dicionários, enciclopédias, anuários, almanaques e catálogos; publicações, como jornais e revistas; e impressos diversos. 
Depois de levantar todo material necessário de pesquisa, a segunda parte da metodologia é viajar até a ilha de Parintins, Itacoatiara, Autazes e adjacências para entrevistar os indígenas das etnias Muras e Mundurucu, tendo em vista que essas etnias possuem comunidades em Parintins, Itacoatiara e Autazes, ou vão sempre fazer comércio com nela.

Outro caminho que podemos seguir é realizar a entrevista de História Oral com os indígenas, onde é preciso seguir um "caminho" (método). Registrar os depoimentos em fitas ou equipamentos digitais, imagem e som, é também registrar as experiências vividas pelos sujeitos sociais que contribui para a compreensão do passado recente.

História Oral é o registro da história de vida de indivíduos que, ao focalizar suas memórias pessoais, constroem também uma visão mais concreta da dinâmica de funcionamento da trajetória do grupo social ao qual pertence. Segundo Meihy:

A História Oral é um procedimento destinado à constituição de novas fontes para a pesquisa histórica, com base nos depoimentos orais colhidos sistematicamente em pesquisas específicas, sob métodos problemas e pressupostos teóricos explícitos. (MEIHY, 1996, p. 56-7)

Nesse momento, a pesquisa segue em andamento, sendo municiada com referencial bibliográfico da história cultural como forma de embasamento para sustentação da dissertação do trabalho.

\section{RESULTADOS}

As fontes que pesquisamos nos revelaram que as guerras tribais sempre estiveram motivando as sociedades e que se apoiavam numa lógica de guerra para explicar a necessidade do empreendimento belicoso. Como cada tribo via as outras como inimigas e, portanto, como potenciais agressoras, justificam os ataques preventivos contra elas pelas ameaças que óbvia e invariavelmente constituíam. Segundo Marvin Harris:

Os grupos que adotaram instituições de controle de crescimento sobreviveram por mais tempo do que aqueles que deixaram ultrapassar sua capacidade limite de sustentação. As guerras primitivas não resultam de caprichos, nem de necessidades instintivas; são simplesmente um dos mecanismos de regulação que 
ajudam a manter as populações humanas num estado de equilíbrio ecológico, com respeito aos seus territórios. (...) A guerra primitiva [é] um mecanismo de adaptação ecológica. (HARRIS, 1978, p. 58-59)

O sociólogo Florestan Fernandes, entre outras razões, não deixa de apontar também a questão ecológica como fator importante para os conflitos belicosos envolvendo os Tupinambá: "Em virtude dos conhecimentos que possuímos sobre as formas de adaptação dos Tupinambá ao meio natural circundante, sabe-se que a guerra desempenhava um papel relevante na estratégia tribal da luta pela vida" (FERNANDES, 1970, p. 128).

As diferentes tribos indígenas que habitavam a llha de Parintins se viam como inimigas, portanto, como potenciais agressoras, de modo que invariavelmente uma delas tomava a iniciativa para a realização de "ataques preventivos" contra outra.

Segundo à filosofia de Thomas Hobbes (2003), superficialmente condensada na ideia da "guerra de todos contra todos" que teria prevalecido no estado de natureza, é que o homem é movido por seus desejos e aventuras, a guerra em várias sociedades indígenas é prazerosa aos mais jovens e nesse sentido, não hesitaria em matar e destruir seu inimigo.

O medo de serem atacados faz com que as tribos ocasionalmente desfiram ataques preventivos, o que dá às outras aldeias boas razões para empreenderem seus próprios ataques preventivos e impele grupos de aldeias a formar alianças que deixam seus vizinhos mais nervosos (PINKER, 2004, p. 439).

Justificativas morais como essas alicerçavam as guerras intertribais, implicando uma "reciprocidade belicosa" que na prática significava uma situação de conflito permanente. Daí as guerras indígenas constituírem sempre um ingrediente importante, senão, fundamental da vida primitiva.

Segundo Florestan Fernandes (1970), a vingança é a causa da guerra para o Tupinambá. Sua finalidade seria o aprisionamento de inimigos para o sacrifício ritual e a antropofagia cerimonial.

A justificativa desse relato de pesquisa é mostrar que as tribos mais belicosas, mesmo perecendo no tempo, continuam vivas como as tribos indígenas Mura, Mundurucus e que ainda habitam a mesma ilha que foi palco de lutas e guerras de séculos e séculos atrás. 


\section{DISCUSSÕES}

\section{Muras}

Os Muras são a tribo mais conhecida da história colonial da Amazônia; com seus assaltos, causavam medo e pavor nas missões jesuítas na Serra de Parintins, durante a segunda metade do século XVII. Em sua monografia sobre o grupo Mura, publicada em 1948, Curt Nimuendaju afirma que esses índios foram mencionados pela primeira vez, em 1714, numa carta do padre jesuíta Bartolomeu Rodrigues, da missão dos Tupinambaranas. Segundo Curt Nimuendajú, "[...] de todas as tribus da Amazônia foi esta a que mais extenso território occupou, espalhando-se das fronteiras do Peru até o Trombetas. (NIMUENDAJU, 1925, p. 140).

O grupo indígena Mura pertence a uma família linguística menor do sul do Amazonas integrada pelas línguas Mura e Pirahã (RODRIGUES, 1998, p. 81). A Funai dispõe de amplo material de cunho histórico e documental a respeito dos Mura, sendo que os vários postos indígenas que atuaram, e ainda atuam, na região do estado do Amazonas foram instalados no início do século XX pelo então Serviço de Proteção aos Índios/SPI.

Os índios Mura ficaram conhecidos na bibliografia etnográfica como "corsários do caminho fluvial". Viviam em suas próprias canoas, como se fossem suas casas, e se destacavam na resistência à ocupação pelos não índios. De acordo com o naturalista Henry Walter Bates:

Os Mura se tornaram uma tribo de pescadores nômades, que desconhecem a agricultura e todas as artes praticadas por seus vizinhos. Não constroem moradias sólidas e duradouras: vivem em grupos familiais isolados ou em pequenos bandos, errando de um lugar para outro ao longo das margens dos rios e das lagoas onde há mais abundância de peixes e de tartarugas. Em cada lugar onde param temporariamente, eles constroem choças provisórias à beira da água, mudando-se mais para cima ou para baixo do barranco à medida que a água sobe ou desce. (BATES, 1840, p. 129-130)

Sua imagem é marcada por traços guerreiros, destemidos, conhecedores de táticas sui generis de ataque e de emboscada, o que atemorizava e lhes concedia uma enorme fama de "perigosos", principalmente nos idos dos séculos XVII a XIX, quando impediram, por sua presença e força física, o avanço das missões, do comércio português e das ações de cunho militar na Amazônia. 


\section{Mundurucus}

Conhecidos como os "espartanos da Amazônia", os Mundurucu sempre foram apontados como a grande tribo guerreira da Amazônia, desde que surgiram na história da região na segunda metade do século XVIII. Os índios Mundurucus apareceram nos registros históricos por volta de 1770, quando fizeram uma série de devastadores ataques aos povoados localizados à beira do rio Tapajós. Nessa época o território da "Mundurucânia" já era objeto de exploração de colonos lusobrasileiros e algumas aldeias missionárias já haviam sido estabelecidas pelos padres jesuítas.

O objetivo dos Mundurucu será perpetrar uma série de ataques tanto a outras tribos indígenas quanto às comunidades não-índias do vale amazônico. Mas, frequentemente elas se mantinham à caça de inimigos de outras etnias durante vários meses, período que podia chegar a um ano e meio. Essa dedicação à atividade belicosa evidencia a importância da guerra para a sociedade Mundurucu.

Por outro lado, Spix e Martius, ao discorrerem sobre a guerra praticada pelos Mundurucu, afirmam que estes "fazem incursão exclusivamente de dia, e, por isso, veem-se igualmente atacados à noite pelos belicosos Araras". Em sua obra Viagem pelo Brasil, os naturalistas alemães, após extensa viagem por várias regiões do país em 1817-1819, observaram que para os Mundurucu:

A guerra é uma ocupação agradável, mais ainda do que para a maioria das tribos; tudo, desde o princípio parece calculado para eles se fazerem valer na guerra. (...). No ataque, distribuem-se os Mundurucus em extensas linhas; esperam a carga de flechas do inimigo (...) e só então desferem instantaneamente as suas flechas apresentadas pelas mulheres, quando o inimigo, em bando cerrado, já não dispõe de muita munição. (SPIX, VON MARTIUS. 1938, p. 409)

Um dos motivos para a brabeza dos Mundurucu, sendo um ponto complexo de entendimento, e as informações evidenciam, é a caça de cabeças humanas, que se revestiam do mais alto significado naquela sociedade.

Segundo Aires de Casal (1976), os Mundurucu eram chamados pelos indígenas de outras tribos de paiquicés, que significava "corta-cabeça", prática essa de que não se tem notícia em qualquer outra tribo indígena do Brasil. 
O teórico acima se confunde aqui, porque tanto índios Parintintins como índios muras, também são cortadores de cabeças. Todos os inimigos homens adultos eram mortos, enquanto as mulheres e crianças eram levadas para as aldeias Mundurucu; aquelas mais tarde se casavam com homens deste grupo, enquanto estas eram adotadas e tratadas como crianças comuns. As cabeças dos homens eram decepadas, preparadas por um processo que ficou conhecido como mumificação e, depois, mantidas como troféus de inestimável valia para os Mundurucu.

As cabeças dos inimigos e, nesse caso, por inimigo se entende qualquer outra etnia, em particular aquele que se e a mantinham - depois de devidamente mumificada e enfeitada - como o mais valioso troféu que se podia exibir. Ela simbolizava o feito máximo a que qualquer homem podia aspirar, o que resultava em orgulho extremado e respeito - provavelmente também inveja - dos seus pares. 0 dono da cabeça - exuberante em prestígio e glória - conduzia-a frequentemente implantada numa estaca e se tornava o elemento central de uma série de festividades e cerimônias celebrantes da cabeça- troféu, que, segundo Murphy, se estendia por três estações chuvosas após a guerra em que havia sido conquistada.

O inimigo, depois de morto, tinha sua cabeça decepada pelo captor com o auxílio de uma lâmina de bambu que lhe cortava o pescoço e a vértebra. Depois, retiravam-se os músculos internos, os miolos, os olhos e a língua para se proceder à mumificação que se fazia pela exposição continuada da cabeça à fumaça do óleo de copaíba, posto a ferver e, em seguida, pela lavagem e banho em azeite de urucu. $O$ crânio não era retirado, de modo que a peça mantinha o tamanho próximo ao original; era preenchido com algodão e depois se colocavam nele olhos de resina, processo que se completava com o implante de dentes de animais e um enfeite de penas que fazia da cabeça um belo troféu que permanecia por um largo período inseparável do seu possuidor. É interessante notar que não se registram cabeças de não índios tomadas como troféus pelos guerreiros Mundurucu, apesar dos incontáveis ataques e mortes infligidas aos colonos luso-brasileiros que habitavam as paragens por eles percorridas. (MURPHY,1954, p. 54).

As guerras intertribais beneficiavam também os portugueses, que viam com bons olhos o enfraquecimento da resistência indígena ao seu domínio, favorecendo - através de uma espécie de escravidão dissimulada - uma utilização cada vez maior da mão-de-obra indígena nas vilas dos colonizadores. 
Devido à grande combatividade desses índios, eles foram recrutados pelos brancos para fazer face a tribos hostis. Com isso os Mundurucu conseguiram manter, por um longo período, certa integridade e autonomia tribal e o poder político dos seus chefes alcançado pelo relevante papel que exerciam na guerra. Assim, os padrões guerreiros passaram a ser desempenhados tanto pelas antigas motivações tribais, como por razões mercenárias. (RIBEIRO, 1979, p. 40)

É o que observa o professor Darcy Ribeiro, que também destaca a aliança guerreira entre os Mundurucu e as forças da coroa portuguesa.

\section{CONSIDERAÇÕES FINAIS}

A questão principal que moveu esse trabalho foi buscar identificar os personagens que participaram ativamente das guerras tribais na Amazônia colonial portuguesa. Ao mesmo tempo, como eles passaram a sobreviver com a imposição da cultura portuguesa, e das políticas da coroa lusitana nesse período.

Dentre as tribos pesquisadas, apenas os Tupinambás pereceram no tempo, foram caçados e exterminados pela coroa portuguesa, O sociólogo Florestan Fernandes, em sua Tese de Doutorado intitulada "A função Social da Guerra na Sociedade Tupinambá", nos brinda com o poder belicoso da tribo tupinambá frente aos inimigos, assim como o historiador Almir Diniz Carvalho Júnior, que nos conta em sua Tese de Doutorado "Índios Cristãos: Poder, Magia e Religião na Amazônia Colonial" de uma batalha sangrenta que aconteceu aos arredores da cidade de Belém, onde duas nações tupinambás se juntaram, uma vinda de Pernambuco e outra do Maranhão, para atacar repetidas vezes os acampamentos em torno da cidade de Belém, fazendo tática de guerrilha, deixando a cidade às escuras, sem abastecimento e sobressaltadas por seus ataques que duraram longos 3 anos.

São esses personagens esquecidos pela historiografia brasileira que pretendemos contar nesse relato, por que foi através desse empreendimento belicoso que muitas prosperam e não foram exterminadas que é o caso dos índios Muras que ainda vivem nos arredores do Rio Madeira, onde que vários relatos de viajantes, pediam o seu extermínio por serem indolente e belicosos. Os mundurucus foram a nação mais promissora desta época, inteligentes e guerreiros, logo aprenderam a fazer políticas com os portugueses e colocaram à disposição da coroa 
portuguesa a "máquina de guerra mundurucu" que era capaz de percorrer quilômetros e quilômetros só para buscar seus preciosos troféus as cabeças inimigas.

Por fim, essa pesquisa vem retratar de forma acadêmica e cientifica que a Amazônia Colonial Portuguesa dos séculos XVII e XVIII não foi entregue aos portugueses sem luta e resistência por parte das nações indígenas. Os portugueses se sobressaíram, utilizando as brigas internas que já existiam antes da vinda de Cabral por essas terras, utilizando as rivalidades que cada tribo inimiga tinha umas das outras e essa foi a grande vantagem do conquistador.

\section{REFERÊNCIAS}

ACUÑA, Cristóbal. Novo descobrimento do grande rio das Amazonas. Rio de Janeiro, Agir, 1994.

BAENA, Antonio Ladislau Monteiro. Observação ou notas illustrativas dos primeiros capítulos da parte segunda do thesouro descoberto no Rio Amazonas. Revista do Instituto Histórico e Geográfico Brasileiro, Rio de Janeiro, v.5, p. 275-311, 1885.

BATES, Henry Walter. O naturalista no Rio Amazonas. São Paulo, 1944.

BENCHIMOL, Samuel. Introdução aos autos de devassas dos índios Mura (1738). Manaus, Universidade do Amazonas, 1985.

CARVAJAL, Gaspar de. Relación que escrebió Fr. Gaspar de Carvajal, Fraile de la Orden de Santo Domingo de Guzmán, del nuevo descubrimiento del famoso Rio Grande que Descubrio por muy gran ventura el Capitán Francisco de Orellana desde su nacimiento hasta salir a la mar, con cincuenta y siete hombres que trajo consigo y se echo a su ventura por el dicho rio, y por el nombre del capitan que le descubrio se llamo el Rio de Orellana. In: CARVAJAL, ALMESTO \& ROJAS, A de. La aventura del Amazonas. Ed. de Rafael Díaz. Madrid, História 16, 1986 (Crónicas de América 19).

CASAL, Manuel Aires de. Corografia Brasílica. Belo Horizonte, Itatiaia, 1976.

CARVALHO JÚNIOR, Almir Diniz de. Índios Cristãos: poder, magia e religião na Amazônia colonial. Curitiba, CVR, 2017.

CERVO, Amado Luiz. Metodologia científica6. ed. - São Paulo, Pearson Prentice Hall, 2007.

FERNANDES, Florestan. A função social da guerra na sociedade Tupinambá. 2. ed. São Paulo, Pioneira, 1970. 
GIL, Antônio Carlos, Como Elaborar Projetos de Pesquisa. 4. ed. São Paulo, Ed. Atlas, 2002.

HARRIS, Marvin. Vacas, porcos, guerras e bruxas: os enigmas da cultura. Rio de Janeiro, Civilização Brasileira, 1978.

HOBBES, Thomas. Leviatã ou Matéria, Forma e Poder de uma República Eclesiástica e Civil. Organizado por Richard Tuck. Tradução de João Paulo Monteiro e Maria Beatriz Nizza da Silva. São Paulo, Martins Fontes, 2003.

LAKATOS, Eva M.; Marconi, Marina de A. Ciência e conhecimento científico. São Paulo, Atlas, 2001.

MEIHY, J.C.S.B. Manual de História Oral. 2. ed. São Paulo, Loyola, 1996, p. 56-7.

MÉTRAUX, Alfred. A religião dos Tupinambás - e suas relações com as das demais tribos Tupi-Guaranis. Trad. Estevão Pinto. 2. ed. São Paulo, Companhia Editora Nacional, 1979.

NIMUENDAJÚ, Curt. Os Indios Parintintin do Rio Madeira. In: Journal de la Société des Américanistes. Tome 16, 1925. pp. 201- 278.

MONTEIRO, John Manuel. De índio a Escravo. A transformação da população indígena de São Paulo no século XVII. Revista de Antropologia. São Paulo, Universidade de São Paulo, 1989.

MURPHY, Robert; MURPHY, Yolanda. As condições atuais dos Mundurucu. Belém, Instituto de Antropologia e Etnologia do Pará, 1954.

PEQUENO, Eliane da Silva Souza. Mura guardiães do caminho fluvial. Revista de Estudos e Pesquisas, FUNAI, Brasília, v.3, n.1/2, p.133-155, jul./dez. 2006

PEREIRA, Nunes. Os índios Maués. 2. ed. Manaus, Valer e Governo do Estado do Amazonas, 2003.

PINKER, Stven. Tábula rasa: a negação contemporânea da natureza humana. São Paulo, Companhia das Letras, 2004.

RIBEIRO, Darcy. Os índios e a civilização. 2. ed. Petrópolis, Vozes, 1979.

RODRIGUES, João Barbosa. Exploração e estudos do Vale do Amazonas: Rio Tapajós. Rio de Janeiro, Typographia Nacional, 1875.

Tribo dos Mundurucus. Revista da Exposição Anthropologica Brasileira. Rio de Janeiro, 1882.

SANTOS, Francisco Jorge dos. Os Munduruku. Boletim Informativo do Museu Amazônico. Manaus, vol. 5, n. 8, 1995, pp. 5-23.

SPIX, J. B.; MARTIUS, K. F. von. Viagem pelo Brasil, 1938, vol. 3.

VIVEIROS DE CASTRO, E. Araweté: Os Deuses Canibais. Rio de Janeiro, Jorge Zahar Editores/Anpocs, 1986. 